\title{
Moraxella catarrhalis
}

National Cancer Institute

\section{Source}

National Cancer Institute. Moraxella catarrhalis. NCI Thesaurus. Code C76210.

A species of gram-negative, aerobic, oxidase-positive diplococcus bacteria within the phylum Proteobacteria that causes upper respiratory tract infections, particularly in immunocompromised hosts. 